\title{
Hand grip forces during chain saw operation and vibration white finger in lumberjacks
}

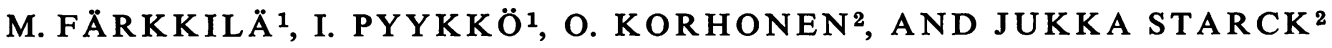 \\ From the ${ }^{1}$ Institute of Physiology, University of Helsinki, and the ${ }^{2}$ Institute of Occupational Health, \\ Helsinki, Finland
}

ABSTRACT The hand grip forces at the front and rear handles of a chain saw were measured during work, in 89 professional lumberjacks. The symptoms caused by vibration to the upper limbs were compared with the hand grip force (HGF) during work. To allow better comparison between subjects we used the ratio of hand grip force (HGF) to the maximal voluntary compression force (MVC), HGF/MVC expressed as a percentage. The mean HGF during sawing varied from 5 to $12 \mathrm{~N}$ in all subjects. The variation in HGF was greater at the front handle than at the rear handle, during sawing. The lumberjacks who had vibration-induced white fingers (VWF), had a higher HGF/MVC in both hands than the lumberjacks without VWF. Those lumberjacks affected by VWF used over $12 \%$ of their MVC at work. Subjects without VWF used less than $7 \%$ of their MVC. The lumberjacks experiencing pain in the arms had a low HGF/MVC ratio. The lumberjacks with and without numbness in their hands had equal HGF/MVC ratios.

Vibration syndrome is prevalent among workers exposed to occupational vibration. The syndrome consists of symptoms relating to blood circulation, peripheral nerves and to muscles (Agate, 1949; Hellström and Lange-Andersen, 1972; Seppäläinen, 1972). The vascular component of the syndrome, vibration-induced white fingers (VWF) (Taylor, 1974) has been most extensively studied.

Several factors provoking the vibration syndrome have been suggested, including vibration frequency and acceleration, the manner in which the tool is handled and the compression force (Taylor, 1974). The asymmetrical division of the hand symptoms in association with many tools (St. Clair Renard, 1963; Hellström and Lange-Andersen, 1972; Kakósy and Szepesi, 1973; Färkkilä et al., 1978) has been attributed either to asymmetric vibration intensities (St. Clair Renard, 1963) or to grip forces during work (Kakósy and Szepesi, 1973). The differences in the incidence of vibration syndrome are believed to be dependent on the grip forces during work (Teisinger, 1972; Kakósy and Szepesi, 1973).

Reprint requests to: $\mathrm{Dr}$ Markus Färkkilä, Institute of Physiology, University of Helsinki, Siltavuorenpenger 20 a, FIN-00170 Helsinki 17, Finland.

Received for publication 4 January 1979

Accepted for publication 9 May 1979
Laboratory measurements have shown that a rise in hand grip force increases the transmission of vibration to the upper limbs (Pyykkö et al., 1976). Besides the direct increase in vibration level, the muscle tension causes phase shifts in the vibration. As a result, the harmful high-frequency vibration (Hyvärinen et al., 1973) increases and is damped and absorbed in the fingers and palm of the hands, causing the symptoms of vibration syndrome (Hempstock and O'Connor, 1974; Suggs, 1974; Pyykkö et al., 1976).

In this investigation we studied the grip forces of professional lumberjacks during work. The subjective symptoms of vibration disease were correlated with the hand grip force and tension used during the work with chain saws.

\section{Material and methods}

We examined 89 professional lumberjacks of the Suomussalmi area in Northern Finland during the annual compulsory medical examination. The mean age of the subjects was $37.8 \mathrm{yr}$ (range 18-54 yr). The medical examination included a history of the symptoms associated with the vibration syndrome.

Histories of white fingers, numbness of the hands, muscle force reduction and pains in the upper limbs were used to classify the subjects. The area of the 
affected phalanges was examined, but the severity of the symptom was not used as a criterion. A cold provocation test (Pyykkö, 1974), was applied to all the 20 lumberjacks complaining of white fingers, and was positive in 12 cases $(60 \%)$. Patients with primary Raynaud's disease, arterial hypertension, diabetes mellitus, or collagenoses were excluded. All the lumberjacks who complained of white finger in either hand were considered to have VWF.

The vibration exposure time was counted from the subjects' responses to questions on how many hours they used the chain saw daily (breaks excluded), how many days they worked in a month, how many months they worked in a year, and how many years they had worked in such a manner. Lumberjacks who had sawn for less than 1500 hours were excluded from the study, which therefore involved 89 lumberjacks, of whom 20 had white fingers (VWF), 10 claimed diminished grip force, 35 had a history of numbness in the hands and 31 had a history of pain in the hands. These represent the total numbers of symptoms, and there were subjects who had several concurrent symptoms.

A group of matching pairs was selected for the 20 lumberjacks with VWF, from the remaining 69 professional lumberjacks. These control subjects, who were of the same age, and had the same chain saw exposure time, as the 20 subjects with VWF, could have other symptoms affecting their upper limbs, but not white fingers.

The tests were performed using a Partner R 22 chain saw (technical specifications in Table 1). Dynamometers were incorporated into the front and rear handles of the saw. They consisted of two metal bars with the original dimensions of the handles of the saw. Strain gauges were fixed on the inner surface of the bars (semiconductor strain gauge KSN-2-E3-11, Kyova). The output voltage of the strain gauges was traced with an automatic recording pen (Watanabe H611). The dynamometers were calibrated by placing the handle between two metal plates (width about $8 \mathrm{~cm}$ ), and loads of 1,5 and $10 \mathrm{~kg}$ were then used to determine the linear relation of the output voltage and force in newtons.

At the beginning of the test each subject compressed both handles in their usual working position

Table 1 Technical specifications of Partner $R 22$ chain saw 1972

\begin{tabular}{lc}
\hline Weight, with petrol & $9.01 \mathrm{~kg}$ \\
Motor stroke volume & $55 \mathrm{~cm}^{3}$ \\
stroke length & $36 \mathrm{~mm}$ \\
maximum speed & $12000 \mathrm{rev} / \mathrm{min}$ \\
idling speed & $2200 \mathrm{rev} / \mathrm{min}$ \\
Chain coupling speed & $3500 \mathrm{rev} / \mathrm{min}$ \\
efficiency length & $38.0 \mathrm{~cm}$ \\
division $(3 / 8$ in) & $9.53 \mathrm{~mm}$ \\
\hline
\end{tabular}

with bare hands at their maximum voluntary contraction (MVC) for about two seconds (Fig. 1). The subjects cut slices of pine logs (diameter $20-25 \mathrm{~cm}$ ) four times. The logs were three metres long, and were supported on two other logs during sawing. The subjects sawed twice downwards and twice upwards. This procedure was selected because about one-third of sawing consists of lifting the saw from the lower to the upper surface of the log. In addition, although other directions of sawing are common in normal work, especially during branching, these vary from one job to another; we therefore used only these two standardised positions. Everyone was instructed to use his normal way of sawing, without time limits.

The tests were carried out in barracks, where the temperature was between $15^{\circ}$ and $18^{\circ} \mathrm{C}$. The subjects

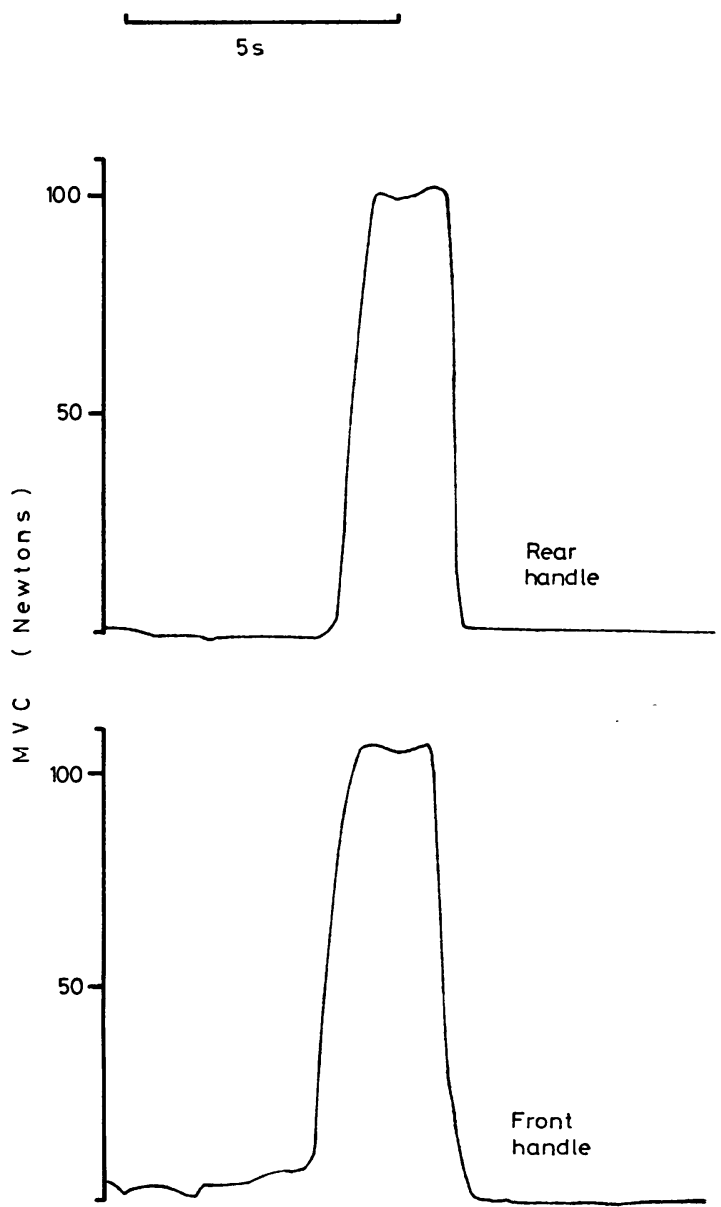

Fig. 1 Measurement of the maximal voluntary contraction $(M V C)$ on the handles of the saw. 

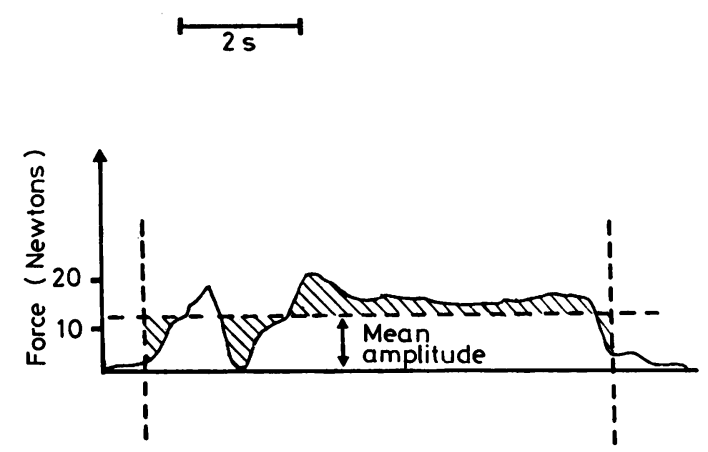

Fig. 2 Example of the muscle force curve. The mean amplitude was used in the results. The lined areas above and below the amplitude line were visually estimated to be equal.

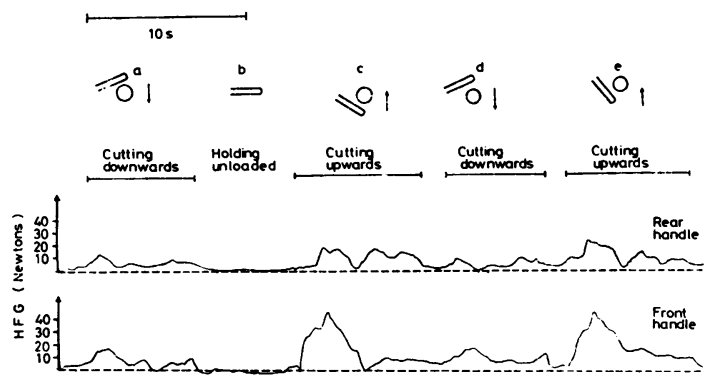

Fig. 3 Measurement of hand grip force during sawing by a professional lumberjack (right-handed, age $48 \mathrm{yr}$ ) who suffered from $V W F$, but did not have numbness in hands or a history of diminished grip force. He had sawn for $13200 \mathrm{~h}$. Figures $a, c, d$ and e represent the four stages of downward and upward cutting.

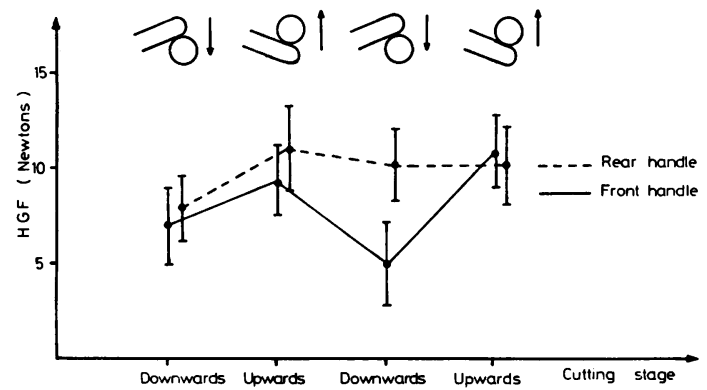

Fig. 4 The hand grip forces of 89 lumberjacks during the four stages used in the test (mean and standard error of mean).

used helmets with hearing protectors. Exhaust gases were ventilated.

The force measurements were read by one investigator from the recorder, as follows (Fig. 2). A mean amplitude was measured for each phase of cutting, so that the areas above and below the mean line were equal (visual estimation). The mean amplitude of grip force during the four stages was used to represent the force (HGF) of the subject. In the results we used the ratio HGF/MVC for comparison of subject groups. The forces during sawing were calculated from a baseline, which was equal to the force needed to hold the unloaded saw in the hands (about $88 \mathrm{~N}$ ). Hence, the results do not include the force used to overcome the weight of the saw, which was the same for all subjects. The gauge was adjusted to read zero, when the subject held the unloaded saw in his hands without compressing the handles.

To test the level of significance of the results, two statistical methods were used. Student's $t$ test for unpaired data was chiefly employed, but to test the significance of the differences between curves as in Figure 6 (not crossing each other) the one-way analysis of variance (multiple $t$ method) was used. The significance level is quoted after the results.

\section{Results}

A typical recording of the muscle force in the front and rear handles of the saw during work is shown in Figure 3 . The HGF varied widely in different subjects, the greatest mean individual HGF being about $30 \mathrm{~N}$. Some lumberjacks cut the logs with hardly any HGF because the saw was leaning on the log while sawing downwards. During downwards cutting most subjects used less HGF in the front handle than during cutting upwards. The HGF in the rear handle was quite independent of the direction of sawing. The HGFs in the front and rear handles were at the same level, but the changes in HGF were greater in the front handle. The HGF from the front handle was normally used in the results, unless it is specifically mentioned that the HGF refers to the force in the rear handle. The mean HGF of all the subjects varied between 5 and $12 \mathrm{~N}$ during work (Figure 4). Sudden high peak values in the HGF were observed, mainly when there was a change in the direction of cutting.

Among lumberjacks of the same age and with similar exposure to sawing (Table 2), the mean HGF was $8.9 \mathrm{~N}$ in subjects with VWF and $5.5 \mathrm{~N}$ in those without VWF. The MVC did not differ significantly between these groups.

The HGF did not depend on sawing time. There was no linear regression of HGF on sawing time among those with VWF $(r=0 \cdot 14)$ and those without $(r=0 \cdot 36)$. Figure 4 shows the HGF in different age groups and in different sawing-time groups. The differences are not statistically significant. Further- 
Table 2 Comparison of force measurements of lumberjacks with and without VWF (age- and sawing time-matched pairs)

\begin{tabular}{|c|c|c|c|c|c|}
\hline \multirow[t]{2}{*}{ Subjects } & \multicolumn{5}{|c|}{ Variables (mean $\pm S D)$} \\
\hline & $\begin{array}{l}\text { Age } \\
(y r)\end{array}$ & $\begin{array}{l}\text { Sawing time } \\
\text { (h) }\end{array}$ & $\begin{array}{l}\text { Maximal voluntary } \\
\text { contraction } \\
\text { (newtons) }\end{array}$ & $\begin{array}{l}\text { Hand grip force } \\
\text { (HGF) } \\
\text { (newtons) }\end{array}$ & $\begin{array}{l}\text { HGF/MVC ratio } \\
(\%)\end{array}$ \\
\hline $\begin{array}{l}\text { Lumberjacks with VWF } \\
(N=20)\end{array}$ & $42 \cdot 0 \pm 6 \cdot 7$ & $11400 \pm 3040$ & $78 \cdot 3 \pm 55 \cdot 2$ & $8 \cdot 87 \pm 6.2$ & $12 \cdot 3 \pm 8 \cdot 2$ \\
\hline $\begin{array}{l}\text { Lumberjacks without VWF } \\
(\mathrm{N}=20)\end{array}$ & $41 \cdot 7 \pm 7 \cdot 1$ & $11530 \pm 4540$ & $83.0 \pm 62.0$ & $5 \cdot 48 \pm 4 \cdot 6$ & $6.4 \pm 6.8$ \\
\hline Student's $t$ test & $\begin{array}{l}t=0.36 \\
\mathrm{P}=\mathrm{NS}\end{array}$ & $\begin{array}{l}t=0.07 \\
\mathrm{P}=\mathrm{NS}\end{array}$ & $\begin{array}{l}t=0.8 \\
P=N S\end{array}$ & $\begin{array}{l}t=2.68 \\
P<0.01\end{array}$ & $\begin{array}{l}t=1.96 \\
P<0.05\end{array}$ \\
\hline
\end{tabular}

more, no differences were found in HGF/MVC, when the classification shown in Figure 5 was used. The HGF/MVC of lumberjacks with and without VWF is seen in Figure 6. The lumberjacks with VWF had a greater HGF/MVC ratio than those without. This difference was statistically significant $(P<0.01)$. Figure 7 shows the percentage of lumberjacks with VWF in different HGF/MVC groups. The linear correlation is significant $(\mathrm{r}=0.92 ; \mathrm{P}<0.01)$. The mean HGF/MVC ratio of lumberjacks with VWF was $12.3 \%$ of the MVC, and the mean HGF/MVC of those without VWF was $6.4 \%$ of the MVC; this difference is statistically highly significant $(t=5.654 ; \mathrm{P}<0.001)$.

Table 3 shows the forces measured. The lumberjacks with a history of numbness in hands and arms had an HGF/MVC ratio during work similar to that found in those without numbness. The lumberjacks who had a history of diminished grip force used about $30 \%$ less HGF/MVC during sawing and had a lower HGF/MVC than those with a history of normal hand grip force. The HGF/MVC ratio of the

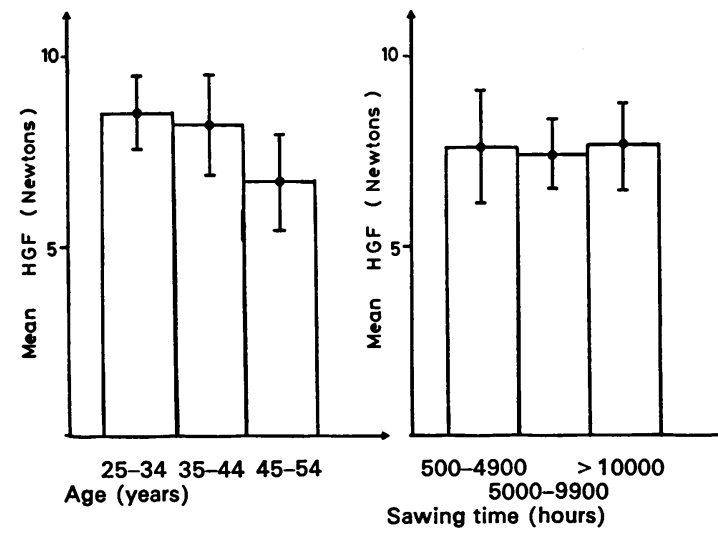

Fig. 5 The hand grip forces in different age- and sawing-time groups of 89 lumberjacks (mean and standard error of mean).

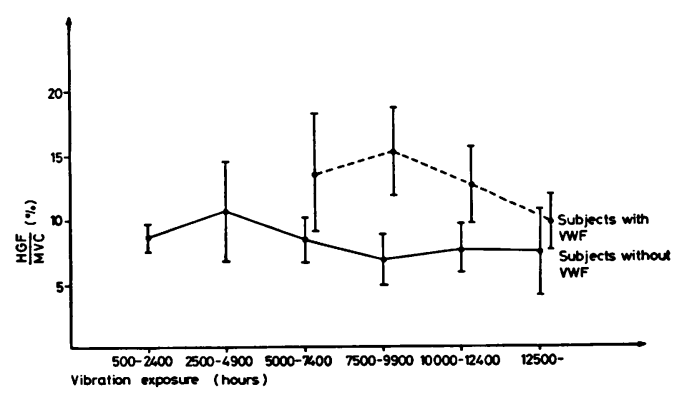

Fig. $6 H G F / M V C$ ratio (\%) at the front handle for 20 lumberjacks with, and 69 without, VWF (mean and standard error of mean).

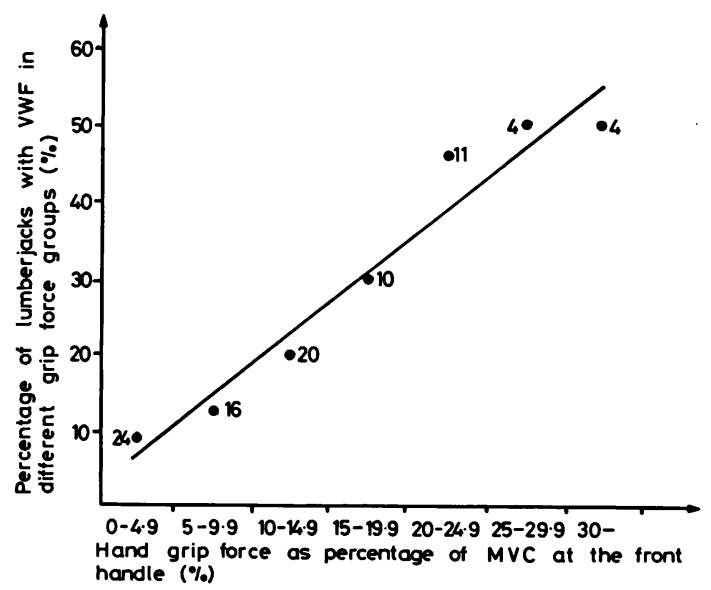

Fig. 7 The percentage of lumberjacks with VWF in different grip force groups, the force measured at the front handle. The numbers beside the points are number of subiects. 
Table 3 Force measurements in lumberjacks with or without the three major symptoms

\begin{tabular}{|c|c|c|c|c|c|c|c|c|c|}
\hline \multirow{2}{*}{$\begin{array}{l}\text { Force measurements } \\
(\text { mean } \pm S D)\end{array}$} & \multicolumn{3}{|c|}{ Reduced grip force } & \multicolumn{3}{|c|}{ Pain in hands } & \multicolumn{3}{|c|}{ Numbness in hands } \\
\hline & $\begin{array}{l}\text { Present } \\
(N=10)\end{array}$ & $\begin{array}{l}\text { Absent } \\
(N=79)\end{array}$ & $\begin{array}{l}\text { Statistical } \\
\text { significance }\end{array}$ & $\begin{array}{l}\text { Present } \\
(N=31)\end{array}$ & $\begin{array}{l}\text { Absent } \\
(N=58)\end{array}$ & $\begin{array}{l}\text { Statistical } \\
\text { significance }\end{array}$ & $\begin{array}{l}\text { Present } \\
(N=35)\end{array}$ & $\begin{array}{l}\text { Absent } \\
(N=54)\end{array}$ & $\begin{array}{l}\text { Statistical } \\
\text { significance }\end{array}$ \\
\hline $\begin{array}{l}\text { Maximal voluntary contraction } \\
\text { (newtons) }\end{array}$ & $\begin{array}{l}98 \cdot 86 \\
\pm 50 \cdot 48\end{array}$ & $\begin{array}{l}96 \cdot 04 \\
\pm 46 \cdot 80\end{array}$ & $\begin{array}{l}t=1 \cdot 22 \\
\mathrm{P}=\mathrm{NS}\end{array}$ & $\begin{array}{l}94 \cdot 03 \\
\pm 54 \cdot 34\end{array}$ & $\begin{array}{l}93 \cdot 98 \\
\pm 43 \cdot 78\end{array}$ & $\begin{array}{l}t=0.65 \\
\mathrm{P}=\mathrm{NS}\end{array}$ & $\begin{array}{l}103 \cdot 04 \\
\pm 45 \cdot 15\end{array}$ & $\begin{array}{l}89 \cdot 11 \\
\pm 47 \cdot 85\end{array}$ & $\begin{array}{l}t=8.94 \\
P<0.001\end{array}$ \\
\hline $\begin{array}{l}\text { Hand grip force (HGF) } \\
\text { (newtons) }\end{array}$ & $\begin{array}{l}5 \cdot 59 \\
\pm 2 \cdot 60\end{array}$ & $\begin{array}{l}8 \cdot 64 \\
\pm 8 \cdot 43\end{array}$ & $\begin{array}{l}t=3.24 \\
P<0.005\end{array}$ & $\begin{array}{l}6 \cdot 43 \\
\pm 7 \cdot 42\end{array}$ & $\begin{array}{l}9 \cdot 39 \\
\pm 8 \cdot 67\end{array}$ & $\begin{array}{l}t=4.63 \\
P<0.001\end{array}$ & $\begin{array}{c}7 \cdot 83 \\
\pm 6 \cdot 54\end{array}$ & $\begin{array}{l}9 \cdot 58 \\
\pm 9 \cdot 54\end{array}$ & $\begin{array}{l}t=2.78 \\
P<0.01\end{array}$ \\
\hline $\begin{array}{l}\text { Hand grip force (HGF/MVC) } \\
\text { ( } \% \text { of MVC) }\end{array}$ & $\begin{array}{l}5.89 \\
\pm 3.43\end{array}$ & $\begin{array}{l}8 \cdot 50 \\
\pm 8 \cdot 20\end{array}$ & $\begin{array}{l}t=2.80 \\
P<0.01\end{array}$ & $\begin{array}{l}5 \cdot 55 \\
\pm 6 \cdot 25\end{array}$ & $\begin{array}{l}9 \cdot 57 \\
\pm 8 \cdot 47\end{array}$ & $\begin{array}{l}t=6.50 \\
P<0.001\end{array}$ & $\begin{array}{r}8 \cdot 49 \\
\pm 8 \cdot 24\end{array}$ & $\begin{array}{l}9 \cdot 54 \\
\pm 8 \cdot 28\end{array}$ & $\begin{array}{l}t=1.648 \\
\mathrm{P}=\mathrm{NS}\end{array}$ \\
\hline
\end{tabular}

lumberjacks with pain in their hands was only half that found in those without pain.

The HGF/MVC of lumberjacks who had sawn for over 10000 hours and who did not have any symptoms of vibration disease, was less than that of the other lumberjacks, the difference being statistically significant $(t=3.026 ; \mathrm{P}<0.005)$.

\section{Discussion}

The lumberjacks withVWF used more HGF than those of the age- and exposure-matched lumberjacks who did not have VWF. The difference is even greater if the HGF/MVC ratios are compared. The mean MVC of the lumberjacks with VWF was less than that of lumberjacks without VWF, which partly explains the greater difference between the HGF/MVC ratios, than between the HGFs. In previous investigations it was found that reduction of maximal grip force is not associated with white fingers (Färkkilä, 1978). The grip force in the hands depends upon age; there is no significant difference in the MVCs of the lumberjacks with and without VWF, and the comparison group was matched according to age and sawing time (Table 2). In the present study the lumberjacks with VWF (20 men) were fairly old, and this explains their lower MVC compared with the other subjects, i.e. the groups in Table 3. The HGF/MVC ratios differ significantly among the age- and exposure-matched groups, and we base our conclusion, that tight grip has harmful effects, on this comparison. Subjects using a tight grip during work are liable to suffer from vasospastic symptoms. The HGF/MVC ratio was used because of the great variation in MVC between lumberjacks (Färkkilä, 1978), and allows stricter comparison between different subjects and their working habits, because it excludes the differences in compression caused by anatomical variation in hand dimensions.

In order to avoid the vibration syndrome, various factors are considered to be of importance: the weight of the saw should be reduced, but a simul- taneous increase in the vibration level should be avoided (Näslund, 1974). The tool should be handled as loosely as possible without losing proper control of the saw. Gloves should be used to spread the grip to a larger area of the hands (Taylor et al., 1971). The subjects who were not accustomed to chain sawing had a very strong HGF when sawing. These subjects also took longer to cut the log. This supports the statement of Teisinger (1972) that unskilled workers hold their tools more tightly and are more prone to acquire the vibration disease.

It is possible that the lumberjacks with VWF might compress the handles tighter because of reduced sensory and proprioceptive control of hand grip force. This does not seem likely, however, because those with numbness in their hands do not compress the handles as much as those with VWF. It seems, therefore, that VWF is probably caused by tight grip. A numb hand would have less HGF because of the neuropathy possibly associated with numbness in the hands.

According to laboratory measurements of the transmission of vibration in the hand and arm, the compression of the handle increases the acceleration of vibration measured in different parts of the upper extremity (Hempstock and O'Connor, 1974; Suggs, 1974; Pyykkö et al., 1976). The increase in vibration level of the hand and arm is proportional to the cube root of the compression force (Pyykkö et al., 1976). For example, an increase in grip force from 8 to $14 \mathrm{~N}$ causes an increase of about $2 \mathrm{~dB}$ in the vibration level at the wrist. The mean HGF/MVC ratio of lumberjacks with VWF was higher (Fig. 7), so that the increased transmission of vibration to the hand is possibly another cause of VWF. The HGF/MVC ratio was higher among those with VWF, independent of the time of exposure to a chain saw.

The HGF/MVC of the lumberjacks with pain in their hands was only half that observed in those without hand pain. The sawing time in these two groups was not equal; the lumberjacks with pain in the hands had a much longer exposure to vibration 
and they were also older. Pain in the upper limbs can be caused by static overloading of muscles. It may be that these subjects have initially used a high degree of muscle tension when sawing but have reduced this because of pain. Thus, the wrist and hand pain may be associated with the previous technique.

The MVCs were similar in those who complained of diminished grip force and those who did not (Table 3). However, during sawing those with reduced grip force used a lower HGF than did those with a history of normal grip force. Those with a reduced grip force may have relaxed their HGF, knowing that they would become fatigued more rapidly. Previous studies have shown that this symptom is particularly prevalent during vibration exposure (Färkkilä, 1978).

The numbness of the hands was not dependent on the HGF/MVC ratio used at work. The MVC of those with numbness in their hands was higher than the MVC of those without. During sawing the HGF was reduced to a greater extent in those with hand numbness. This could have been caused by a vibration neuropathy which affects muscle contraction during vibration.

When operating the chain saw the lumberjacks use only about $5-15 \%$ of the MVC; hence the fatigue phenomenon does not appear during the measurements (Gollnick et al., 1974).

These measurements reveal differences in grip forces between workers. Our results show that an increase in the HGF/MVC ratio is correlated with a higher risk of VWF. Every effort should be made to diminish the grip force, by such means as modifying the design of the handles of the tools, the use of special gloves, counselling lumberjacks, and changing working methods; all these strategies are recommended in order to prevent the vascular symptoms of vibration syndrome.

We thank Ekströmin Koneliike for offering the Partner chain saw used in this study.

\section{References}

Agate, J. N. (1949). An outbreak of cases of Raynaud's phenomenon of occupational origin. British Journal of
Industrial Medicine, 6, 144-163.

Färkkilä, M. (1978). Grip force in vibration disease. Scandinavian Journal of Work, Environment and Health, 4, 159-166.

Färkkilä, M., Starck, J., Hyvärinen, J., and Kurppa, K. (1978). Vasospastic symptoms caused by asymmetrical vibration exposure of the upper extremities to a pneumatic hammer. Scandinavian Journal of Work, Environment and Health, 4, 330-335.

Gollnick, P. D., Karlsson, J., Piehl, K., and Saltin, B. (1974). Selective glycogen depletion in skeletal muscle fibres of man following sustained contractions. Journal of Physio$\log y, 241,59-67$.

Hellström, B., and Lange-Andersen, K. (1972). Vibration injuries in Norwegian forest workers. British Journal of Industrial Medicine, 29, 255-263.

Hempstock, T. I., and O'Connor, D. E. (1974). The vibration characteristics of several engineering processes which produce white finger. In The Vibration Syndrome, pp. 51-60. Edited by W. Taylor. Academic Press: London.

Hyvärinen, J., Pyykkö, I., and Sundberg, S. (1973). Vibration frequencies and amplitudes in the aetiology of traumatic vasospastic disease. Lancet, 1, 791-794.

Kakósy, T., and Szepesi, L. (1973). Effects of vibration exposure on the localization of Raynaud's phenomenon in chain saw operators. Work-Environment-Health, 10, 134-139.

Näslund, U. (1974). Design problems in the reduction of vibration in chain saws. In The Vibration Syndrome, pp. 61-70. Edited by W. Taylor. Academic Press: London.

Pyykkö, I. (1974). The prevalence and symptoms of traumatic vasospastic disease among lumberjacks in Finland. WorkEnvironment-Health, 11, 118-131.

Pyykkö, I., Färkkilä, M., Toivanen, J., Korhonen, O., and Hyvärinen, J. (1976). Transmission of vibration in the hand-arm system with special reference to changes in compression force and acceleration. Scandinavian Journal of Work, Environment and Health, 2, 87-95.

Seppäläinen, A.-M. (1972). Peripheral neuropathy in forest workers. A field study. Work-Environment-Health, 9, 106-111.

St. Clair Renard, K. G. (1963). Kärlkramp vid borrningsarbete. Meddelanden frän Svenska gruvföreningen, 7, 1-55.

Suggs, G. W. (1974). Modelling of the dynamic characteristics of hand-arm system. In The Vibration Syndrome, pp. 169-186. Edited by W. Taylor. Academic Press: London.

Teisinger, J. (1972). Vascular disease disorders resulting from vibrating tools. Journal of Occupational Medicine, 14, 129-133.

Taylor, W. (1974). The vibration syndrome: Introduction. In The Vibration Syndrome, pp. 1-12. Edited by W. Taylor. Academic Press: London.

Taylor, W., Pearson, J., Kell, R. L., and Keighley, G. D. (1971). Vibration syndrome in Forestry Commission chain saw operators. British Journal of Industrial Medicine, 28, 83-89. 